\title{
Comparison of the water potential baseline in different locations. Usefulness for irrigation scheduling of olive orchards
}

\author{
M. Corell, D. Pérez-López, M.J. Martín-Palomo, A. Centeno, I. Girón, A. Galindo, \\ M.M. Moreno, C. Moreno, H. Memmi, A. Torrecillas, F. Moreno, A. Moriana
}

Keywords:

Plant water status measurements

Oil olive

Table olive

Water relations

\begin{abstract}
A B S T R A C T
Deficit irrigation scheduling needs accurate indicators and in recent decades, continuous plant indicators have been developed. However, threshold values that could be useful in commercial orchards are not commonly reported. The water potential is a discontinuous measurement commonly used as a reference in the description of water stress level. In some fruit trees, such as olive trees, there are several works suggesting threshold values in fully irrigated conditions, but the influence of the evaporative demand is not taken into account. The aim of this work is to compare the values of the fully irrigated water potential in different locations in order to study the estimation of a common baseline. Three mature olive orchards were selected, two in Seville (South Spain) and one in Ciudad Real (Central Spain). There were clear differences between the three orchards during the 2015 season. Orchards in Seville (S-1 and S-2) were close (10 km apart) and had the same cultivar (table olive, cv Manzanilla) but they were different in terms of the fruit load (almost no fruit in S-1, medium fruit load in S-2) and distribution of water (single drip line in S-1, double drip line in S-2). The orchard in Ciudad Real (CR) was very different with regards to the olive cultivar (cv Cornicabra) and the location, as it was in a borderline zone for olives growing with very low temperatures that delay the phenological development. In all the orchards, the best baseline was obtained with different climatic measurements, even in S-1 and S-2. When all the data were considered, the best fit was obtained with the average vapour pressure deficit (VPDav). Influence of the location was significant in the interception term of the equations when Temperature was used but not with VPD. This source of variation was reltade with the level of fruit load. Slope of the equations was not affected for the location. The equation obtained was validated with water potential data from previous seasons of S-1 and CR orchards. Maximum temperature presented the best validation results. The usefulness of this baseline is discussed.
\end{abstract}

\section{Introduction}

Water for agricultural uses progressively decreases in arid zones because of the scarcity of natural resources and the increase in water demand for other social uses (Fereres and Soriano, 2007).
The climate change models estimate that in these zones rainfall will decrease and temperature will increase, consequently the evaporative demand will rise. (IPCC, 2015). In addition, traditional rainfed fruit crops in these zones, such as olive trees, are converted into more dense, irrigated orchards. These species are usually drought resistant and farmers receive less irrigation water than the real needs of the orchard. Olive trees are a good example, with more than 400,000Ha on irrigated land in Spain (MAGRAMA, 2016) where most of the surface experiences deficit irrigation conditions. 
Nowadays there is a wide variety of soil and plant sensors available, even for commercial orchards, and they could be used to schedule deficit irrigation conditions (i.e., zim probe, dendrometry, canopy temperature). However, to our knowledge, little is known about the water stress threshold level of these tools. Thus, at least in olive orchards, the technology related to the design of new sensors is ahead of the sensor management in the field, understood as the knowledge about the stress threshold values that the plants can be subjected to. Although midday stem water potential is not the earliest indicator of water stress in olive trees (Moriana and Fereres, 2002), it is used as the standard comparison for most of the new sensors. Moriana et al. (2012) suggested using -1.2 and $-1.4 \mathrm{MPa}$ of midday stem water potential as the threshold for fully irrigated olive trees. However, according to literature, values below $-1.4 \mathrm{MPa}$ are common, mainly in mid-summer or in high fruit load seasons in fully irrigated treatments (i.e. Martín-Vertedor et al., 2011).

Plant measurements have been considered very efficient tools for irrigation scheduling (Turner, 1990) although they were not traditionally used due to their close relationship with evaporative demand (Hsiao, 1990). Shackel et al. (1997) was one of the first works that suggested irrigation scheduling for fruit trees based on the water potential. Nevertheless, the influence of evaporative demand when suggesting water potential threshold values is not commonly considered in the literature (i.e. plum, Lampinen et al., 2001; citrus, Ballester et al., 2013; pecan, Othman et al., 2014; olive, Moriana et al., 2012; Rosecrance et al., 2015; Girón et al., 2015). For continuous indicators, such as dendrometry, it is very common to estimate the baseline (Ortuño et al., 2010). Because these methodologies have a great amount of data, baseline estimations at the beginning of the season are easier to obtain than in water potential measurements. The great sensitivity of plant measurements to the tree physiology also increases the difficulty of obtaining a strong baseline, especially when different cultivars or environments are considered. Thus, few works have been published about the comparison of thresholds or approaches between significantly different locations. The aim of this work is to compare the seasonal baseline of the water potential in different olive orchards in order to verify if a unique estimation would be comparable and useful.

\section{Material and methods}

\subsection{Orchards locations}

Three experimental orchards were considered for the comparison of baselines:

1. Seville 1 (S-1). This orchard is located in La Hampa, the experimental farm of the Instituto de Recursos Naturales y Agrobiología (IRNAS-CSIC) in Coria del Río, near Seville (Spain) $\left(37^{\circ} 17^{\prime} \mathrm{N}, 6^{\circ}\right.$ $3^{\prime} \mathrm{W}, 30 \mathrm{~m}$ altitude). The sandy loam soil (about $2 \mathrm{~m}$ deep) of the experimental site was characterized by a volumetric water content of $0.33 \mathrm{~m}^{3} \mathrm{~m}^{-3}$ at the saturation point, $0.21 \mathrm{~m}^{3} \mathrm{~m}^{-3}$ at field capacity and $0.1 \mathrm{~m}^{3} \mathrm{~m}^{-3}$ at the permanent wilting point, and a bulk density of $1.30(0-10 \mathrm{~cm})$ and $1.50(10-120 \mathrm{~cm}) \mathrm{g} \mathrm{cm}^{-3}$. The experiment was performed on 44-year-old table olive trees (Olea europaea L cv Manzanillo) during the 2015 season. Tree spacing followed a $7 \mathrm{~m} \times 5 \mathrm{~m}$ square pattern. Irrigation was carried out during the night by drip, using one lateral pipe per row of trees and five emitters per plant, delivering $8 \mathrm{~L} \mathrm{~h}^{-1}$ each.

2. Seville 2 (S-2). This orchard is located in Doña Ana, a private farm in Dos Hermanas, near Seville (Spain) ( $\left.37^{\circ} 25^{\prime} \mathrm{N}, 5^{\circ} 95^{\prime} \mathrm{W}\right)$. The loam soil (deeper than $1 \mathrm{~m}$ ) of the experimental site was characterized by a volumetric water content of $0.31 \mathrm{~m}^{3} \mathrm{~m}^{-3}$ at field capacity and $0.14 \mathrm{~m}^{3} \mathrm{~m}^{-3}$ at the permanent wilting point, and a bulk density of $1.4(0-30 \mathrm{~cm})$ and $1.35(30-90 \mathrm{~cm}) \mathrm{g} \mathrm{cm}^{-3}$. The experiment was performed on 30-year-old table olive trees (Olea europaea L cv Manzanillo) during the 2015 season. Tree spacing followed a $7 \mathrm{~m} \times 4 \mathrm{~m}$ square pattern. Irrigation was carried out during the night by drip, using two lateral pipes per row of trees and twenty-six emitters per plant, divided between the two rows, delivering $2 \mathrm{Lh}^{-1}$ each.

3. Ciudad Real (CR). This orchard is located in "El Chaparrillo", the experimental farm of Consejeria de Agricultura (Junta de Castilla La Mancha) in Ciudad Real, Central Spain, $\left(39^{\circ} 02^{\prime} \mathrm{N}, 3^{\circ}\right.$ $94^{\prime} \mathrm{W}$, altitude $640 \mathrm{~m}$ above sea level). The soil is a shallow clayloam (Petrocalcic Palexeralfs) 0,75 m deep and a discontinuous petrocalcic horizon between $0.75-0.85 \mathrm{~m}$. The volumetric water content was for was $26.0 \%$ after field capacity and $13.1 \%$ at wilting point. The experiment was performed on 17-years-old olive trees (Olea europaea L cv Cornicabra) during the 2015 season. Tree spacing followed a $7 \mathrm{~m} \times 4.76 \mathrm{~m}$ square pattern. Irrigation was carried out during the night by drip, using one lateral pipe per row of trees and four emitters per plant, delivering $8 \mathrm{Lh}^{-1}$ each.

\subsubsection{Climatic description}

The climatic conditions of the orchards located in Seville are almost equal because the distance between them is only around $10 \mathrm{Km}$ and both of them are at the same level in the Guadalquivir Valley. The distance between Ciudad Real and Seville is around $330 \mathrm{Km}$ and there are a great differences in altitude $(640 \mathrm{~m}$ vs $30 \mathrm{~m}$ above sea level) and in the distribution of rains and temperatures. Fig. 1 presents the seasonal pattern of reference evapotranspiration (ETo), rain and temperature in both locations during the 2015 season. Winter minimum temperatures are clearly different between both locations. While Seville is slightly below $0^{\circ} \mathrm{C}$, some data of Ciudad Real are in the region of $-10^{\circ} \mathrm{C}$. These minimum temperatures indicate that Seville is a traditional olive zone while Ciudad Real is in the borderline where this fruit tree can be cultivated. Although summer temperatures are similar in both locations, the delay in the recovery of spring temperatures causes a shorter growing season in Ciudad Real than in Seville and the date of flowering is very different: around mid-April in Seville and early-June in Ciudad Real. During 2015, seasonal rains were slightly lower in Seville than in Ciudad Real (Fig. 1b). In both locations, late-spring and summer are dry periods and evaporative demand is extremely high.

Table 1 summarises the fruit load of the three orchards considered during the 2015 season in comparison with the historical average. The CR orchard has a lower average yield than the $S-1$ and S-2 orchards due to the important problems with low winter temperatures. The current yield, the one obtained in the 2015 season, was clearly different between locations. The CR orchard presents a record yield in comparison with the historical average (two fold more than the average). On the other hand, S-1 and S-2 were lower than the average with almost no fruit load in the S-1 orchard.

\subsubsection{Irrigation regimes and measurements}

All the measurements were made on six to eight trees (depending on the orchard) located in a plot with adjacent guard rows. The water status of the trees for each treatment was characterized by the midday stem water potential $(\Psi)$ and maximum leaf conductance. The leaves near the main trunk were covered in aluminium foil at least one hour before measurements were taken. The water potential was measured at midday in one leaf per tree, using the pressure chamber technique (Scholander et al., 1965) every 7-10 days. Leaf conductance was measured with permanent porometer (S1 and S2 orchards, Decagon) and with an IRGA (CR 

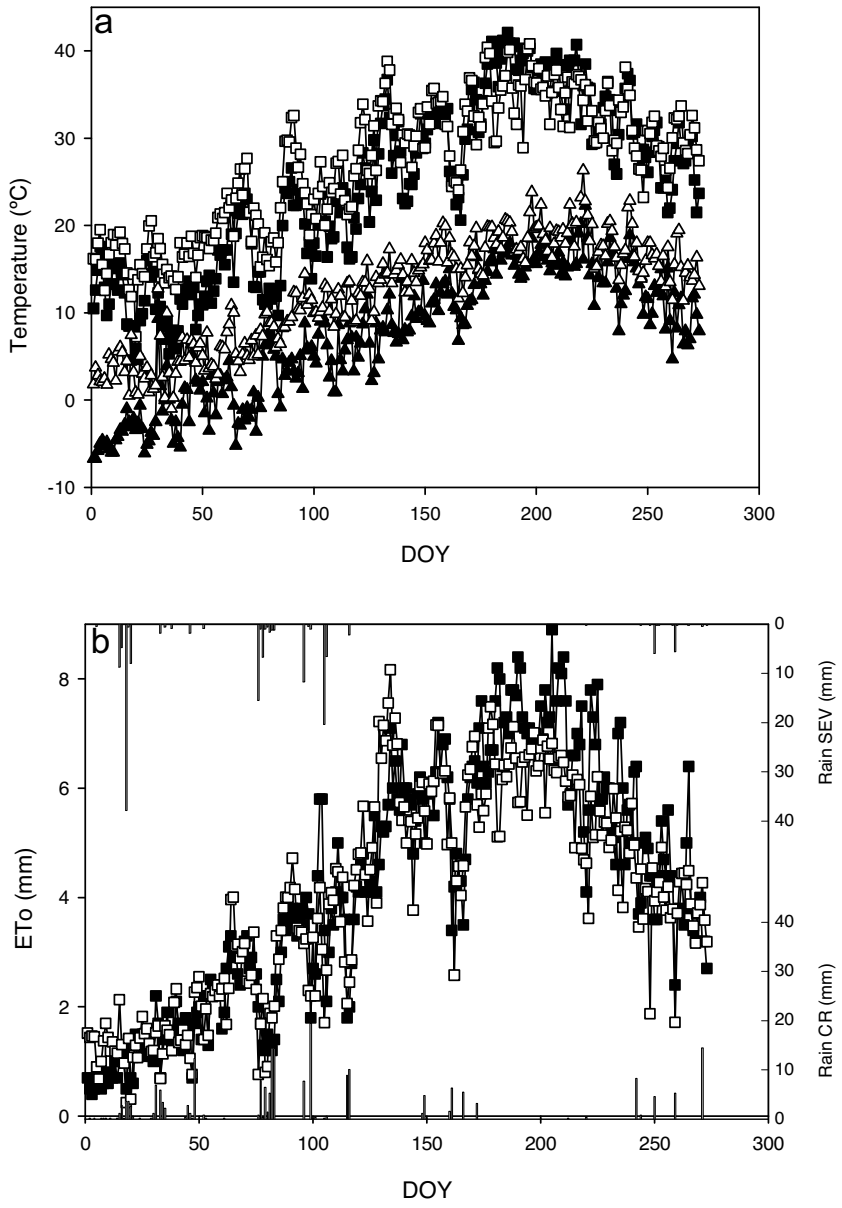

Fig. 1. Seasonal pattern of the climatic variables in Seville (empty symbols) and Ciudad Real (full symbols). (a) Maximum and minimum temperatures (b) Reference evapotranspiration (ETo) and rain. All the data were obtained from automatic weather station near (around $100 \mathrm{~m}$ ) to the experimental orchards named as CR and S1.

orchard, CIRAS-1, pp system). Problems with the IRGA limited the period of measurements to only the beginning of the season. Leaf conductance daily cycle in olive tree presents a maximum during the morning and a minimum during midday (Xiloyannis et al., 1988). Moriana et al. (2002) reported than maximum leaf conductance was more sensitive to water stress than minimum values. According to this result, values of maximum leaf conductance were estimated in S1 and S2 orchards. Because the IRGA measurements spend more time than porometer and leaf conductance values are dynamics, minimum leaf conductance was measured in CR orchard.

Trees were irrigated with more than $100 \%$ of crop evapotranspiration (ETc) in order to maintain the midday stem water potential values higher than $-1.4 \mathrm{MPa}$ (according to the value suggested in Moriana et al., 2012). Because midday stem water potential values were lower than this threshold in the CR and S- 1 orchards during some periods, the applied water was greater (four fold) than in S-2 (Table 1).
Micrometeorological 30 min data, namely air temperature, solar radiation, relative humidity of air and wind speed at $2 \mathrm{~m}$ above the soil surface, were collected by an automatic weather station located some $40 \mathrm{~m}$ from the experimental site in the S-1 orchard and around $100 \mathrm{~m}$ in the CR orchard. The daily reference evapotranspiration (ETo) was calculated using the Penman-Monteith equation (Allen et al., 1998). The mean daily vapour pressure deficit (VPD) was calculated from the mean daily vapour pressure and relative humidity. The maximum daily vapour pressure deficit (VPD) was calculated from the minimum daily vapour pressure and relative humidity. The climatic variables considered were: minimum and average VPD, maximum, minimum and average temperature, minimum and average relative humidity and ETo. Climatic data measured at the S-1 orchard were used in the relationships between S-1 and S-2 orchards.

The soil moisture was measured with a portable FDR sensor (HH2, Delta-T, U.K. in Seville orchards and Diviner, 2000, Sentek Pty. Ltd., Australia in Ciudad Real orchard) with a calibration obtained in previous works. The measurements were made in three to four plots per orchard. The access tubes for the FDR sensor were placed in the irrigation line at about $30 \mathrm{~cm}$ from an emitter, which is the distance where root activity is higher (Fernández et al., 1991). The data were obtained at $1 \mathrm{~m}$ depth with $10 \mathrm{~cm}$ intervals.

A linear regression analysis was carried out to explore the relationships between variables (midday stem water potential and climatic variables) in each location and considered all the three orchards with 2015 season data. Adjusted coefficient of determination $\left(R^{2}\right)$ was considered only in multi-variable models, otherwise coefficient of determination as used. Differences between regression lines were determined with a T-test of the slope and y-intercept (Statistic SX 8.0). The random effect due to the locations were analysed with mixed model using the library "nlme" in $\mathrm{R}$ program (R 3.3.1; R Core Team, 2016). Random effects in the interception and slope terms were considered. The selection of the best model was based on the results obtained in the lineal (MSE and $\mathrm{R}^{2}$ ) and mixed models (AIC). Data from different seasons (2014 in the S-1 orchard and 2012 and 2013 in the CR orchard) were used to validate the relationships obtained. Values of relative humidity (in\%) were transformed with arcosin function to avoid heterocedasticity.

\section{Results}

The soil water content $(\theta)$ is presented in Fig. 2 for the three locations of the experiment. The seasonal pattern of $\theta$ was very similar for all locations. At the beginning of the season values were low because irrigation had not started. However, even these minimum values were not limiting in any of the locations considered. The irrigation increased $\theta$ but measured values were almost constant and commonly lower than field capacity in all the locations. Only S-1 values were higher than field capacity during most of the summer. In the other two locations, CR and S-2, $\theta$ values were no limiting, if $70 \%$ of the available water is considered as the threshold value (Goldhamer and Fereres, 1990).

The seasonal pattern of midday stem water potential and leaf conductance for the three orchards are presented at Fig. 3. Water potential values varied from near $-0.5 \mathrm{MPa}$ to slightly below of $-2 \mathrm{MPa}$ (Fig. 3a). In S-1 and S-2, measurements began before than

Table 1

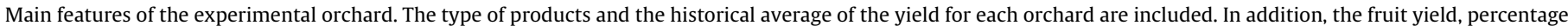
of soil cover and applied water during the experimental season is presented.

\begin{tabular}{|c|c|c|c|c|c|}
\hline Location & Type of product & Average yield & \% Soil Cover & Current yield & Applied Water \\
\hline S-1 & Table olive & $8 \mathrm{MT} \mathrm{ha}^{-1}$ & $56 \%$ & $0.2 \mathrm{MT} \mathrm{ha}^{-1}$ & $452 \mathrm{~mm}$ \\
\hline S-2 & Table olive & $9 \mathrm{MT} \mathrm{ha}^{-1}$ & $32 \%$ & 3.6 $\mathrm{MT} \mathrm{ha}^{-1}$ & $158 \mathrm{~mm}$ \\
\hline CR & Oil olive & 4.5 MT ha $\mathrm{M}^{-1}$ & $33 \%$ & 8.2 $\mathrm{MT} \mathrm{ha}^{-1}$ & $420 \mathrm{~mm}$ \\
\hline
\end{tabular}




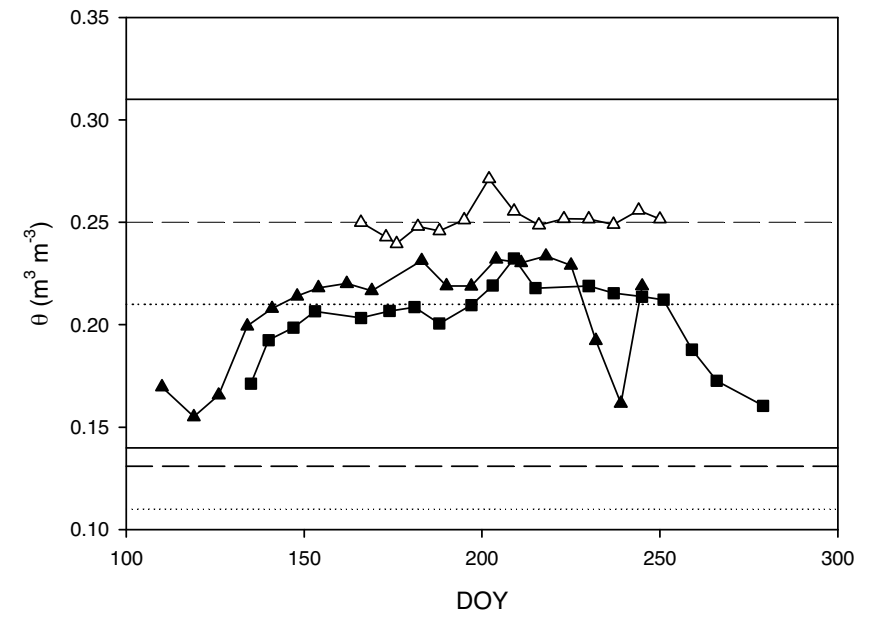

Fig. 2. Seasonal pattern of soil water content $(\theta)$ in the three experimental orchards. CR, Full square and dash line; S-1, full triangle and dot line; S-2, empty triangle and solid line. Horizontal lines represent the field capacity and permanent wilting point of the soils. Each point is the average of 4 measurements in CR and S-2 orchards and 3 in S-1 orchards.
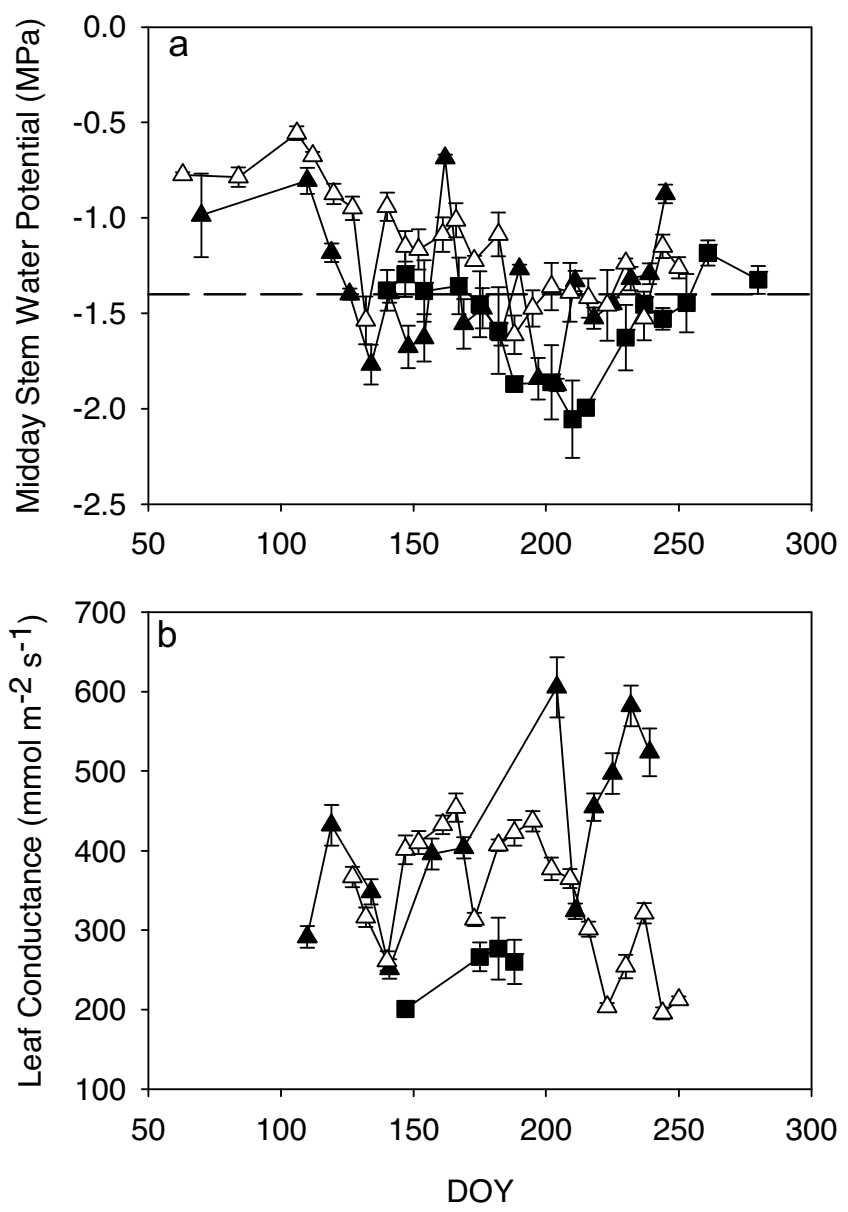

Fig. 3. Pattern of midday stem water potential (a) and leaf conductance (b) in the three experimental orchards. Full square, CR; Full triangle, S1; Empty triangle S2. Each point is the average of 6-8 data depending of the orchard consider. Vertical bars represent standard error. Horizontal dash line in figure "a" shows the threshold value of water potential for the three orchards $(-1.4 \mathrm{MPa})$.
CR orchard and in these dates (end of winter/beginning of spring) maximum values were obtained. Most of values were around $-1.4 \mathrm{MPa}$, the threshold selected, but in S-1 and CR locations around DOY (day of the year) 188 until DOY 237, water potential decreased until minimum values. In this period, on the contrary, S-2 orchard presented almost constant values arund $-1.4 \mathrm{MPa}$. Leaf conductance measurements in $\mathrm{CR}$ locations were not much because of the problem with the equipment. The values obtained in this site are near of the ones reported in the literature for full irrigated trees using the same methodology (Moriana et al., 2002). In S-1 and S2 orchards, leaf conductance values were similar at the beginning of the season, but from DOY 204 until the end of the experiment, values measured at S-1 was clearly higher than the one obtained at S-2.

Table 2 summarises the results of the regressions at the $C R$ orchard. In this location, the multi-variable model was not better than the ones presented in Table 2. All the climatic measurements considered were closely related to the midday stem water potential $(\Psi)$. In this location, temperature measurements presented the best agreement with $\Psi$ (around 0.75 of $\mathrm{R}^{2}$ ), while relative humidity indicators were clearly the worse (values $\mathrm{R}^{2}$ around 0.35 ). All the climatic measurements considered values that implied a greater evaporative demand and reduced $\Psi$. The greater slope of the regression was obtained for the transformed relative humidity (HRav $1.13 \mathrm{MPa}^{-1}$, $\mathrm{HRmin}^{2.24} \mathrm{MPa}^{-1}$ ) while the lower was in temperature (between $\operatorname{Tmax}-0.04 \mathrm{MPa}{ }^{\circ} \mathrm{C}^{-1}$ and $\mathrm{Tmin}-0.05 \mathrm{MPa}^{\circ} \mathrm{C}^{-1}$ ). The best agreement was obtained with minimum temperatures.

The regression results of the $S-1$ orchard are presented in Table 3. In this location the multi-variable approach that includes average VPD (VPDav) and the reference evapotranspiration (ETo) were better than any of the single models. All the climatic variables considered were closely related to $\Psi$. In this location, the relative humidity indicators also presented some weak agreements with $\Psi$ but, in this case, the minimum temperature was the worst $\left(\mathrm{R}^{2}=0.2\right)$. On the contrary, ETo and VPDav, as a single model, showed the best agreement with $\mathrm{R}^{2}$ values around 0.75 . This latter result was significantly improved when both were combined in a multi-variable model (adjusted $\mathrm{R}^{2}=0.82$ ). As in the previous location (CR), $\Psi$ was reduced when all the climatic indicators implied an increase in the evaporative demand. Also as in the previous location, transformed relative humidity presented the greater slope in the regression equation (HRav $1.42 \mathrm{MPa}^{-1}$, HRmin $1.67 \mathrm{MPa} \%^{-1}$ ). The minimum slope was estimated again in the regression equations for temperature (between $\operatorname{Tmin}-0.03 \mathrm{MPa}{ }^{\circ} \mathrm{C}^{-1}$ and $\operatorname{Tmax}-0.06 \mathrm{MPa}^{\circ} \mathrm{C}^{-1}$ ) similar to the ones obtained in the previous location (Table 2).

Table 4 shows the results of the regression equations in the S-2 orchard. As in the CR orchard, any multi-variable model was not significantly better than the single ones presented in the Table. All the climatic variables considered were closely related to $\Psi$. In this location, as in the previous one, the relative humidity shows the weakest relationship $\left(R^{2}=0.31\right)$ although minimum temperature $\left(R^{2}=0.46\right)$, as in the S-1 orchard (Table 3 ), and average VPD $\left(R^{2}=0.51\right)$ are also clearly worse than the rest. As in the previous locations, $\Psi$ was reduced when all the climatic indicators implied an increase in the evaporative demand. Transformed relative humidity was also the equation that presented the greatest slope (HRav, $0.95 \mathrm{MPa}^{-1}$, HRmin $1.04 \mathrm{MPa}^{-1}$ ), while tempearature variables were the lowest (between $\operatorname{Tmax}-0.047 \mathrm{MPa}{ }^{\circ} \mathrm{C}^{-1}$ and Tav $-0.059 \mathrm{MPa}{ }^{\circ} \mathrm{C}^{-1}$ ). In this location, the maximum temperature clearly showed the best equation.

The results of the pool data of the three locations is presented in Table 5. The multi-variable equations containing data of average temperature and average relative humidity were similar to the best single regression $\left(R^{2}=0.68\right.$, in the single equation vs $R^{2}=0.67$ in the multi-variable). All the climatic variables considered were closely related to $\Psi$. The agreement of the regressions was more 
Table 2

Regression analysis of the climatic variable and water potential data at CR orchard. The best fit is marked in bold.

\begin{tabular}{|c|c|c|c|c|c|}
\hline & Constant & Slope & $\mathrm{R}^{2}$ & $\mathrm{~N}$ & MSE \\
\hline VPDav & $-1.0855^{* * * *}$ & $-0.2689^{* * * *}$ & $0.6854^{* * *}$ & 16 & 0.0232 \\
\hline VPDmax & $-0.9813^{* * * *}$ & $-0.1398^{* * * *}$ & $0.7247^{* * *}$ & 16 & 0.0203 \\
\hline ETo & $-0.9265^{* * *}$ & $-0.1062^{* *}$ & $0.4837^{* *}$ & 16 & 0.0381 \\
\hline $\mathrm{HRav}^{\mathrm{a}}$ & $-2.0579^{* * * *}$ & $1.1328^{*}$ & $0.3456^{*}$ & 16 & 0.0483 \\
\hline $\mathrm{HRmin}^{\mathrm{a}}$ & $-1.9922^{* * * *}$ & $2.2458^{*}$ & $0.3566^{*}$ & 16 & 0.0475 \\
\hline Tmax & $-0.3738^{\mathrm{ns}}$ & $-0.0368^{* * * *}$ & $0.7106^{* * * *}$ & 16 & 0.0214 \\
\hline Tav & $-0.5762^{*}$ & $-0.0427^{* * * *}$ & $0.7405^{* * * *}$ & 16 & 0.0192 \\
\hline Tmin & -0.9014 & $-0.0524^{* * * *}$ & $0.7619^{* * * *}$ & 16 & 0.0176 \\
\hline
\end{tabular}

$\mathrm{R}^{2}$-Determination Coefficient. N-Number of data. MSE-Mean Square of Errors. ns-No significative.

${ }^{*} \mathrm{p} \leq 0.05$

** $\mathrm{p} \leq 0.01$

*** $\mathrm{p} \leq 0.001$

**** $\mathrm{p} \leq 0.0001$

a arcosin transformation was made to avoid heterocedasticity.

Table 3

Regression analysis of the climatic variable and water potential data at S-1 orchard. The best fit is marked in bold.

\begin{tabular}{|c|c|c|c|c|c|c|}
\hline & Constant & Slope 1 & Slope 2 & $\mathrm{R}^{2}$ & $\mathrm{~N}$ & MSE \\
\hline VPDav & $-0.7401^{* * * *}$ & $-0.437^{* * * * *}$ & & $0.7437^{* * * *}$ & 21 & 0.0292 \\
\hline VPDmax & $-0.6058^{* * * *}$ & $-0.220^{* * * * *}$ & & $0.6495^{* * * *}$ & 21 & 0.0399 \\
\hline ETo & $-0.2286^{n s}$ & $-0.209^{* * * *}$ & & $0.7491^{* * * *}$ & 21 & 0.0286 \\
\hline $\mathrm{HRav}^{\mathrm{a}}$ & $-2.3601^{* * * * *}$ & $1.4220^{* *}$ & & $0.5394^{* * *}$ & 21 & 0.0525 \\
\hline $\mathrm{HRmin}^{\mathrm{a}}$ & $-1.9041^{* * * *}$ & $1.6661^{* *}$ & & $0.3849^{* *}$ & 21 & 0.0701 \\
\hline Tmax & $0.6834^{\mathrm{ns}}$ & $-0.064^{* * * *}$ & & $0.6700^{* * * * *}$ & 21 & 0.0376 \\
\hline Tav & $0.0772^{\text {ns }}$ & $-0.0598^{* * *}$ & & $0.5661^{* * *}$ & 21 & 0.0494 \\
\hline Tmin & $-0.8544^{* *}$ & $-0.0331^{*}$ & & $0.1964^{*}$ & 21 & 0.0916 \\
\hline VPDav, ETo & -0.3850 & $-0.2382^{*}$ & $-0.1175^{* *}$ & $0.8064^{* * * *}$ & 21 & 0.0209 \\
\hline
\end{tabular}

$\mathrm{R}^{2}$-Determination Coefficient. N-Number of data. MSE-Mean Square of Errors. ns-No significative.

${ }^{*} \mathrm{p} \leq 0.05$.

$\mathrm{p} \leq 0.01$.

${ }^{* * *} \mathrm{p} \leq 0.001$.

**** $\mathrm{p} \leq 0.0001$.

a arcosin transformation was made to avoid heterocedasticity.

Table 4

Regression analysis of the climatic variable and water potential data at S-2 orchard. The best fit is marked in bold

\begin{tabular}{|c|c|c|c|c|c|}
\hline & Constant & Slope & $\mathrm{R}^{2}$ & $\mathrm{~N}$ & MSE \\
\hline VPDav & $-0.7918^{* * * *}$ & $-0.3529^{* * *}$ & $0.5084^{* * *}$ & 24 & 0.0434 \\
\hline VPDmax & $-0.6535^{* * * *}$ & $-0.1709^{* * * *}$ & $0.6396^{* * * *}$ & 24 & 0.0318 \\
\hline ETo & $-0.2336^{\mathrm{ns}}$ & $-0.1803^{* * * *}$ & $0.6131^{* * * *}$ & 24 & 0.0341 \\
\hline $\mathrm{HRav}^{\mathrm{a}}$ & $-1.9285^{* * * *}$ & $0.9476^{* *}$ & $0.3149^{* *}$ & 24 & 0.0605 \\
\hline $\mathrm{HRmin}^{\mathrm{a}}$ & $-1.5706^{* * * *}$ & $1.0441^{* *}$ & $0.3270^{* *}$ & 24 & 0.0594 \\
\hline Tmax & $0.2944^{\mathrm{ns}}$ & $-0.0474^{* * * *}$ & $0.7785^{* * * *}$ & 24 & 0.0195 \\
\hline Tav & $0.1759^{\mathrm{ns}}$ & $-0.0585^{* * * *}$ & $0.7344^{* * * *}$ & 24 & 0.0234 \\
\hline Tmin & $-0.3421^{\mathrm{ns}}$ & $-0.0512^{* * *}$ & $0.4585^{* * *}$ & 24 & 0.0478 \\
\hline
\end{tabular}

$\mathrm{R}^{2}$-Determination Coefficient. N-Number of data. MSE-Mean Square of Errors. ns-No significative.

${ }^{* *} \mathrm{p} \leq 0.01$.

**** $\mathrm{p} \leq 0.001$.

**** $\mathrm{p} \leq 0.0001$

a arcosin transformation was made to avoid heterocedasticity.

Table 5

Regression analysis of the climatic variable and water potential data using the pool data of the three locations. In all the relationship $\mathrm{n}=61$. The best fit is marked in bold

\begin{tabular}{|c|c|c|c|c|c|c|}
\hline & Constant & Slope 1 & Slope 2 & $\mathrm{R}^{2}$ & MSE & AIC \\
\hline VPDav & $-0.82^{* * * *}$ & $-0.38^{* * * *}$ & & $0.68^{* * * *}$ & 0.036 & -24.95 \\
\hline VPDmax & $-0.68^{* * *}$ & $-0.19^{* * * *}$ & & $0.67^{* * * *}$ & 0.038 & -23.15 \\
\hline ETo & $-0.37^{*}$ & $-0.18^{* * * *}$ & & $0.59^{* * * *}$ & 0.047 & -9.47 \\
\hline $\mathrm{HRav}^{\mathrm{a}}$ & $-2.09^{* * * *}$ & $1.11^{* * * *}$ & & $0.52^{* * * *}$ & 0.054 & -0.53 \\
\hline $\mathrm{HRmin}^{\mathrm{a}}$ & $-1.82^{* * * *}$ & $1.52^{* * * *}$ & & $0.46^{* * * *}$ & 0.061 & 9.77 \\
\hline Tmax & $0.25^{\mathrm{ns}}$ & $-0.05^{* * * *}$ & & $0.61^{* * * *}$ & 0.045 & -12.56 \\
\hline Tav & $0.10^{\text {ns }}$ & $-0.05^{* * * *}$ & & $0.51^{* * * *}$ & 0.055 & 0.63 \\
\hline Tmin & $-0.91^{* * * *}$ & $-0.029^{* *}$ & & $0.14^{* *}$ & 0.097 & 35.01 \\
\hline HRav $^{1}$,Tav & $-1.01^{* * * *}$ & $-0.187^{\mathrm{ns}}$ & $-0.34^{* * * *}$ & $0.67^{* * * *}$ & 0.037 & -36.90 \\
\hline
\end{tabular}

$\mathrm{R}^{2}$-Determination Coefficient. N. MSE-Mean Square of Errors. AIC-Akaike information criterion. ns-No significative.

* $\mathrm{p} \leq 0.05$.

** $\mathrm{p} \leq 0.01$.

**** $\mathrm{p} \leq 0.001$.

**** $\mathrm{p} \leq 0.0001$

a arcosin transformation was made to avoid heterocedasticity. 

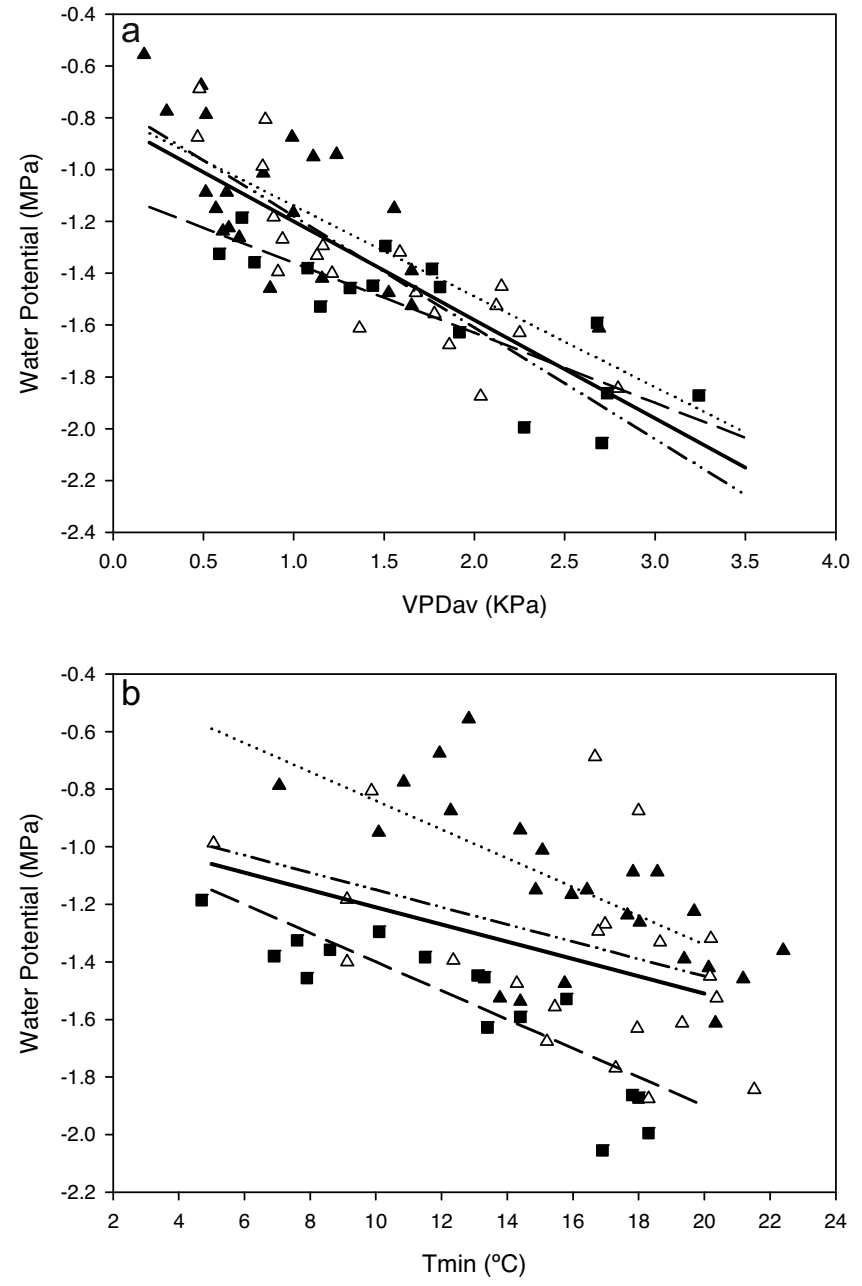

Fig. 4. Relationship between VPDav (a) and Tmin (b) vs midday stem water potential. Square and dash line represent the data of CR orchard. Full triangle and dot lines represent the data of S-1 orchard. Empty data and dot and dash line represent the data of S-2 orchard.

similar when all the data were considered than for separate locations and only minimum temperatures presented a very low $\mathrm{R}^{2}(0.14)$ in comparison with the rest (between 0.46 and 0.68 ). Although relative humidity showed again one of the worse agreements, the pool data were better than at isolated locations. Transformed HR were, again, the ones that presented the greatest slope in the equations (HRav, $1.11 \mathrm{MPa}^{-1}$, HRmin, $1.52 \mathrm{MPa} \%^{-1}$ ) but VPDav and VPDmax showed the best agreements when single models were considered. AIC (Akaike information criterion) is the parameter uses in mixed models for selected the best approach. As low is the AIC, better is considered the predictions of the model. In Table 5, AIC showed the similar results as $\mathrm{R}^{2}$ and MSE; multivariable fit, VPDav and VPDmax were, in this order, according to this parameter the best models. On the other hand, Tmin, both HR and Tav were the worst using the AIC (Table 5).

The Fig. 4 compares the relationship of $\Psi$ vs the two most extreme climatic variables according to their results in the regressions obtained (Table 5), VPDav (Fig. 4a) and Tmin (Fig. 4b). Regressions equations between VDPav and $\Psi$ were more similar between locations than the ones related with Tmin. Such differences occurred even though the values of VPD measured in Seville were slightly higher than the ones in Ciudad Real, while the minimum temperature range was almost the same.

Fig. 4 shows, using the two extreme models as an example, that there could be an effect of the location depending of the climatic measured considered. Mixed models evaluated the effect of the different locations. Results of mixed models consider only random effects in the interception term is shown at Table 6 . In this kind of analysis, the standard deviation due to location is estimated ( $\sigma \mathrm{a})$ and is compared with the one of the error term $(\sigma)$ using the pratio (percentage of $\sigma \mathrm{a}^{2}$ in the total variance). According to the p-ratio, there are two clear groups, one in which the influence of the location is very small (VDPav, VPDmax, HRav, HRmin and the multi-variable model). Other groopu where locations affect the agreement of the model and no unique model could be considered (ETo, but mainly Tmax, Tav, Tmin).

The influence of the locations could affect also to the slope term. Therefore, considering one climatic measured, slope could be different in different locations. This effect is also analysed with mixed models at Table 7 . Not all the climatic measurements are presented at Table 7 because there were not enough interactions to obtain a result using this approach. In all the climatic measured considered, the percentage of the variance explained for changes in the slope ( $p$ ratio) are very low. Such results suggest that slopes are not affected for the location. Otherwise, there are starting conditions which is the main effect of the location in this variable ( $p$-ratios between $40-88 \%$ of the total variance).

All the equations of Table 5, using the whole set of data, were validated with data from different seasons. The best validations are presented at Fig. 5, VPDav (Fig. 5a) and Tmax using single (Fig. 5b) and mixed models (Fig. 5c and d). The equations using in Tmax that include the random effect of interception are presented at Table 8 . There were significant differences between all the fits and the equation $1: 1$. Slopes of equations were significantly different of 1 , though estimations with Tmax were nearer than the ones of VPDav. Equations based on mixed models in Tmax did not improve the validation obtained with single model when the interception coefficients are considered according to the location of the orchard (Fig. 5c, equations of Table 8). Fig. 5 d equations of Table 8 was selected according to fruit load instead of location. Table 8 equation for $\mathrm{CR}$ was used in the validation of $\mathrm{S}-1$ (yield efficiency $1.40 \mathrm{~kg} \mathrm{~m}^{-3}$ ) and CR 2013 season (yield efficiency $1.49 \mathrm{~kg} \mathrm{~m}^{-3}$ ), while equation for S-1 was used in the validation of CR 2012 season (yield efficiency $0.05 \mathrm{~kg} \mathrm{~m}^{-3}$ ). These changes improved the validation in comparison to Fig. 5c, though was similar to Fig. 5b. Data from the CR orchard in the both seasons considered were nearer to a $1: 1$ relationship (slopes 0.72 , VPDav, 0.74 , Tmax and 0.7 and 0.66 Tmax mixed models) that the ones of S-1 (slope 0.34, VPDav, 0.54, Tmax, and 0.53 , in both Tmax mixed models).

\section{Discussion}

Midday stem water potential $(\Psi)$ was always related in the same way in all the locations considered, the increase of evaporative demand (higher temperature, low humidity and so on) reduced the $\Psi$ values. However, each location presented a different optimum climatic measured for a full irrigated model, even the two orchards with the same cultivar and relatively near, such as S- 1 and $\mathrm{S}-2$ (around $10 \mathrm{Km}$ away). Although climate could be considered the same in the S-1 and S-2 orchards, such differences in water relations were likely affected by the irrigation system. In the S-2 orchard there were more drips than in the $S-1$ and this could increase the fraction of roots in wet conditions. Torres-Ruiz et al. (2013) reported differences in the leaf conductance between trees with different fraction of roots in wet conditions, even when they received the same amount of water. In addition, the great differences of water applied in both orchards (Table 1) to obtain a similar water status also behave in this way. Such differences could affect the water potential values and the relationship with climatic measurements. Fernández (2014) suggest that in fully irrigated conditions, 
Table 6

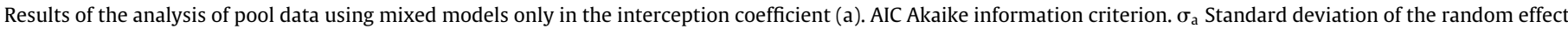
in the interception term. $\sigma$ Standard deviation of the error term. P-ratio. Ratio between variance of the random effect and the total variance $\left(\sigma_{\mathrm{a}}{ }^{2} /\left(\sigma_{\mathrm{a}}{ }^{2}+\sigma^{2}\right)^{*} 100\right)$.

\begin{tabular}{|c|c|c|c|c|}
\hline & AIC & $\sigma_{\mathrm{a}}$ & $\sigma$ & p-ratio (\%) \\
\hline VPDav & -13.61 & 0.0034 & 0.0345 & 0.95 \\
\hline VPDmax & -14.37 & 0.0082 & 0.0325 & 5.93 \\
\hline ETo & -6.91 & 0.0167 & 0.0361 & 17.51 \\
\hline HRav $^{1}$ & 7.99 & $1.714 \mathrm{E}-10$ & 0.0544 & $9.93 \mathrm{E}-16$ \\
\hline $\mathrm{HRmin}^{1}$ & 15.99 & 0.0030 & 0.0627 & 0.23 \\
\hline Tmax & -18.03 & 0.0260 & 0.0280 & 46.23 \\
\hline Tav & -10.94 & 0.0376 & 0.0315 & 58.72 \\
\hline Tmin & 21.72 & 0.0732 & 0.0547 & 64.13 \\
\hline HRav $^{1}$,Tav & -21.08 & 0.0078 & 0.0267 & 7.94 \\
\hline
\end{tabular}

Table 7

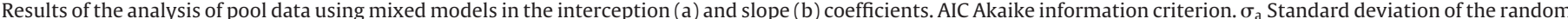

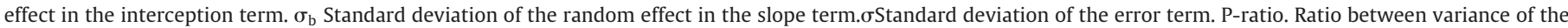
random effect and the total variance.

\begin{tabular}{|c|c|c|c|c|}
\hline & & Variance & P ratio (\%) & AIC \\
\hline \multirow{3}{*}{ Tmin } & $\sigma_{\mathrm{a}}$ & 0.2706 & 57.2 & \multirow{3}{*}{25.72093} \\
\hline & $\sigma_{\mathrm{b}}$ & $1.985 e-06$ & 0 & \\
\hline & $\sigma$ & 0.2340 & 42.8 & \\
\hline \multirow{3}{*}{ Tmax } & $\sigma_{\mathrm{a}}$ & 0.4457 & 88 & \multirow{3}{*}{-16.04042} \\
\hline & $\sigma_{\mathrm{b}}$ & 0.0102 & 0.4 & \\
\hline & $\sigma$ & 0.1623 & 11.6 & \\
\hline \multirow{3}{*}{ ETo } & $\sigma_{\mathrm{a}}$ & 0.3696 & 79 & \multirow{3}{*}{-6.395355} \\
\hline & $\sigma_{\mathrm{b}}$ & 0.0452 & 1.2 & \\
\hline & $\sigma$ & 0.1825 & 19.8 & \\
\hline \multirow{3}{*}{ VDPmax } & $\sigma_{\mathrm{a}}$ & 0.1478 & 40.3 & \multirow{3}{*}{-10.726} \\
\hline & $\sigma_{\mathrm{b}}$ & 0.0193 & 0.7 & \\
\hline & $\sigma$ & 0.1788 & 59 & \\
\hline
\end{tabular}
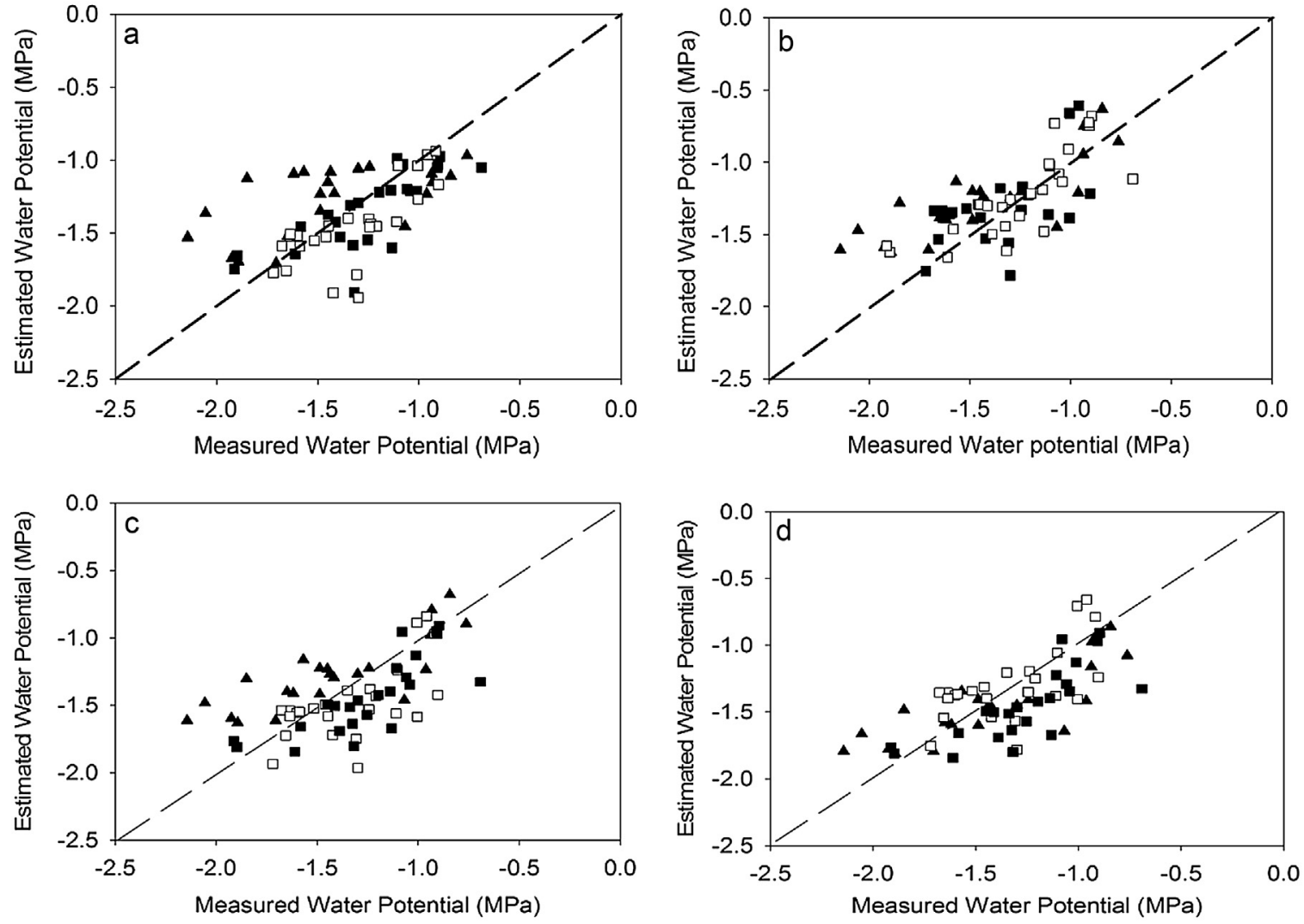

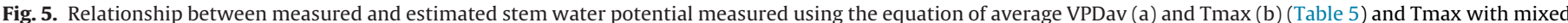

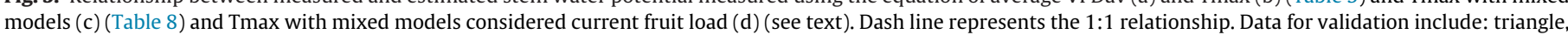

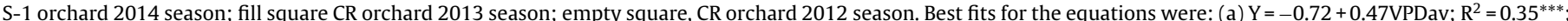
(b) $Y=-0.43+0.62 \mathrm{Tmax} ; \mathrm{R}^{2}=0.51^{* * *} ;$ (c) $\mathrm{Y}=-0.68+0.54 \mathrm{Tmax} ; \mathrm{R}^{2}=0.37^{* * *} ;$ (d) $\mathrm{Y}=-0.60+0.60 \mathrm{Tmax} \mathrm{max}^{* * *} ; \mathrm{R}^{2}=0.48^{* * *}$. 
Table 8

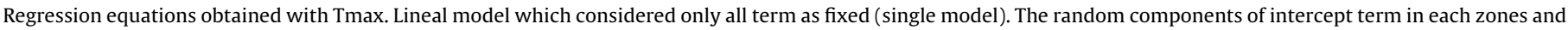
final equations with mixed models. Yield efficiency calculated as the ratio between the yield and tree volume in each location.

\begin{tabular}{|c|c|c|c|c|}
\hline $\mathrm{T} \max$ & Single model & Random components & Final Equations & Yield efficiency $\left(\mathrm{Kg} \mathrm{m}^{-3}\right.$ \\
\hline $\mathrm{CR}$ & & -0.165 & $\Psi=-0.019-0.046 \mathrm{~T} \max$ & 1.63 \\
\hline S-1 & $\Psi=0.146-0.046 \mathrm{Tmax}$ & 0.017 & $\Psi=0.163-0.046 \mathrm{Tmax}$ & 0.02 \\
\hline S-2 & & 0.148 & $\Psi=0.294-0.046 \mathrm{Tmax}$ & 0.31 \\
\hline
\end{tabular}

the water potential is regulated for leaf conductance and this could reduce the decrease caused by the environmental changes. On the other hand, Ciudad Real is a cooler location than Seville. The wider variations in minimum temperature experienced mainly this season in Ciudad Real could be the reason for a better fit of this climatic measurement. Differences in the best climatic measured to predict water status plant indicator have been found commonly such as maximum daily shrinkage (MDS). In olive trees, mean temperature, VPD and maximum temperature have been reported as possible predictors of a fully irrigated baseline of MDS (Moriana and Fereres, 2004; Moreno et al., 2006; Moriana et al., 2011).

The selection of the best baseline predictor should be based in several results when the pool data is used in order to generalize the relationship to other orchards different for the ones where the experiment was performed. Coefficient of determination $\left(R^{2}\right)$ and MSE at Table 5 show that the best agreements are VPDav and VPDmax. Multi-variable equation was almost equal to VPDav, but it should not been considered because the improving does not justify the use of one climatic measured more. The study of the variance in the mixed models shows that, in addition, VPDav had an almost null effect of the locations while VPDmax and mainly Tmax have a great influence of the orchard (Table 6). On the contrary, the analysis of the random effect of the slope showed that there were no differences due to locations (Table 7). Mixed models have not improved the AIC of the single models in VPDav (Table 5 vs Table 6). Therefore, VPDav using the single lineal model was the best fit and the best candidate for obtained a general equation. VPDmax and Tmax could be also interesting approaches but primarily Tmax would have an important source of variations between orchards. Mixed model that considered the random effect in the interception presented the highest AIC in Tmax (Table 5 vs Tables 6 and 7) and should be considered if this parameter is used (Table 8).

One of the possible sources of error between locations could be fruit load. Data from Fig. 4 showed that equations were closer for a medium/high fruit load (S-2 and CR) than for a low fruit load season (S-1). In Table 8, yield efficiency of each orchard is showed. The lowest values of yield efficiency were associated with the higher intercept values in Tmax equation (Table 8). Moreover, the validation using mixed models with Tmax was improved when fruit load instead of locations itself were used. Low fruit load conditions reduced the leaf conductance and increased the water potential (Martín-Vertedor et al., 2011). The lack of influence of fruit load in the VPDs relationships is likely related with the great response of olive trees water relation to this parameter. Olive trees are very sensitive to VPD variations and adjust the daily cycle of gas exchange to the VPD daily patterns (Xiloyannis et al., 1988). Fernández and Moreno (1999) suggested that VPD and radiation are the main drivers for stomata closure. Moriana et al. (2002) reported a lineal relationship between minimum leaf conductance and VPD which changed with water status of the trees. Therefore, VPD could be an easy measurement indicator in commercial orchards, strongly related with tree physiology and probably, with similar relationships even in different locations. On the other hand, interception values fot Tmax equations provide in Table 8 are likely useful, according to the validation results, considering only low, medium or high fruit load and not yield efficiency which is a difficult parameter to estimate in commercial orchards at the beginning of the season.

Water status indicators are strongly affected by the environment and this questions their usefulness as irrigation scheduling tools. Baselines from climatic measurements have been widely used, mainly for continuous indicators such as maximum daily shrinkage. However, from our knowledge, comparisons between different orchards with very different conditions are not reported in the literature. This lack of information limits the commercial applications of these techniques. The results of the present work suggest that a unique equation could be useful enough to determine the effect of the evaporative demand, at least, in commercial conditions. This is very important because the water potential is a discontinuous plant indicator and the number of data available is considerably low in comparison to, for instance, MDS. In most fruit trees, using the first data obtained in the season has been suggested to calculate the estimation of the MDS baseline (Goldhamer and Fereres, 2004; Egea et al., 2009; Corell et al., 2013). Although a similar estimation could be done with water potential, using the first data for the current season, the needs of going to the field and the narrower variations in water potential than in MDS make this an unsuitable strategy, especially in commercial conditions.

The range of $\Psi$ values measured were great, though full irrigated conditions were performed. Although values lower than $-2.0 \mathrm{MPa}$ were not the most common (the average of the data pool was $-1.34 \mathrm{MPa}$ ), some measurements were clearly lower than the ones suggested by Moriana et al. (2012) after pit hardening ( $-1.4 \mathrm{MPa}$ ). Irrigation scheduling approaches based on a constant value of water potential consider negligible the influence of evaporative demand (for instance Moriana et al. (2012) in olives or Lampinen et al. (2001) in prunes). According to the present data, such suggestions will not reduce yield but will over-estimate water needs. In addition, not using a baseline in the determination of threshold values could distort the conclusions, because the effect of the environment could be confused with drought resistance.

\section{Conclusions}

Each orchard location presented differences in the best climatic measurements to fit a baseline. The effect of the location was significant in some equations, mainly the ones related with Temperature, while as almost negligible in others such as VPDs. There were no effects of the location in the slope of the equations considered. VPDav was the best fit when all the data were considered and, according to the present work, could be used as general equation in different locations. Tmax presented the best validation, although it was not the best fit when the whole data is considered. The random effect in the interception of Tmax equation was related with fruit load. Good validation according to fruit load was obtained using the interception values provided in the present work. These baselines (based on VPDav and Tmax), which consider all data, presented a reasonably good fit when validated with data from other seasons and they could be considered as a valid tool, at least in commercial orchards. Maximum temperature could be the most interesting because of the great validation results and because it is the easiest climatic measurement to obtain. The usefulness of these baselines 
is very high in indicators such as water potential, for whom the number of data is limited. The use of these baselines will provide a more accurate estimation of the water needs.

\section{Acknowledgement}

This research was supported by the Spanish Ministerio de Ciencia e Innovación (MICINN), (AGL2013-45922-C2-1-R).

\section{References}

Allen, R.G., Pereira, L.S., Raes, D., Smith, M., 1998. Crop Evaportranspiration. Guideline for Computing Crop Water Requirements. FAO Irrigation and Drainage Paper No. 56. FAO, Roma.

Ballester, C., Castel, J., Intrigliolo, D.S., Castel, J.R., 2013. Response of Navel Lane Late citrus trees to regulated deficit irrigation:yield components and fruit composition. Irrig. Sci. 31, 333-341.

Corell, M., Girón, I.F., Moriana, A., Dell'Amico, J., Morales, D., Moreno, F., 2013. Extrapolating base-line trunk shrinkage reference equations across olive orchards. Agric. Water Manag. 126, 1-8.

Egea, G., Pagán, E., Baille, A., Domingo, R., Nortes, P., Pérez-Pastor, A., 2009. Usefulness of establishing trunk diameter based reference lines for irrigation scheduling in almond trees. Irrig. Sci. 24, 431-441.

Fereres, E., Soriano, M.A., 2007. Deficit irrigation for reducing agricultural water use. J. Exp. Bot. 58, 147-159.

Fernández, J.E., Moreno, F., 1999. Water use by the olive tree. J. Crop Prod. 2 $101-162$.

Fernández, J.E., Moreno, F., Cabrera, F., Arrue, J.L., Martín-Aranda, J., 1991. Drip irrigation, soil characteristics and the root distribution and root activity of olive trees. Plant Soil 133, 239-251.

Fernández, J.E., 2014. Understanding olive adaptation to abiotic streses as a tool to increase crop performance. Environ. Exp. Bot. 103, 158-179.

Girón, I.F., Corell, M., Martín-Palomo, M.J., Galindo, A., Torrecillas, A., Moreno, F., Moriana, A., 2015. Feasibility of trunk diameter fluctuations in the scheduling of regulated deficit irrigation for table olive trees without references trees. Agric. Water Manag. 161, 114-126.

Goldhamer, D.A., Fereres, E., 1990. Deciduous fruit and nut trees. Chap. 33. In: Steward, B.A., Nielsen, D.R. (Eds.), Irrigation of Agricultural Crops. (Agronomy Monograph, 30.). American Society of Agronomy, Madison, pp. 987-1017.

Goldhamer, D.A., Fereres, E., 2004. Irrigation scheduling of almond trees with trunk diameter sensors. Irrig. Sci. 23, 11-19.

Hsiao, T.C., 1990. Measurements of plant water status. Chap. 9. In: Steward, B.A Nielsen, D.R. (Eds.), Irrigation of Agricultural Crops. (Agronomy Monograph, 30.). American Society of Agronomy, Madison, pp. 243-279.

IPCC, 2015. (Intergovernmental Panel on Climate Change). https://www.ipcc.ch/report/ar5/index.shtml.

Lampinen, B.D., Shackel, K.A., Southwick, S.M., Olson, W.H., 2001. Deficit irrigation strategies using midday stem water potential in prune. Irrig. Sci. 20, 47-54.

MAGRAMA (Spanish Agricultural and Environment Ministry), 2016. Yearbook of Agricultural Statistics 2014.
Martín-Vertedor, A., Pérez-Rodriguez, J.M., Prieto, H., Fereres, E., 2011. Interactive responses to water deficits and crop load in olive (Olea europaea L. cv Morisca) I. Growth and water relations. Agric. Water Manag. 98, 941-949.

Moreno, F., Conejero, W., Martín-Palomo, M.J., Girón, I.F., Torrecillas, A., 2006. Maximum daily trunk shrinkage reference values for irrigation scheduling in olive trees. Agric. Water Manag. 84, 290-294.

Moriana, A., Fereres, E., 2002. Plant indicators for scheduling irrigation for young Olive Trees. Irrig. Sci. 21, 83-90.

Moriana, A., Fereres, E., 2004. Establishing references values of trunk diameter fluctuations and stem water potential for irrigation scheduling of olive trees. Acta Hortic. 664, 407-412.

Moriana, A., Villalobos, F.J., Fereres, E., 2002. Stomatal and photosynthetic responses of olive (Olea europaea L.) leaves to water deficits. Plant Cell Environ. 25, 395-405.

Moriana, A., Moreno, F., Girón, I.F., Conejero, W., Ortuño, M.F., Morales, D., Corell, M., Torrecillas, A., 2011. Seasonal changes of maximum daily shrinkage reference equations for irrigation scheduling in olive trees: influence of fruit load. Agric. Water Manag. 99, 121-127.

Moriana, A., Pérez-López, D., Prieto, M.H., Ramírez-Santa-Pau, M., Pérez-Rodriguez, J.M., 2012. Midday stem water potential as a useful tool for estimating irrigation requirements in olive trees. Agric. Water Manag. 112, 43-54.

Ortuño, M.F., Conejero, W., Moreno, F., Moriana, A., Intrigliolo, D.S., Biel, C., Mellisho, C.D., Pérez-Pastor, A., Domingo, R., Ruiz-Sánchez, M.C., Casadesus, J., Bonany, J., Torrecillas, A., 2010. Could trunk diameter sensors be used in woody crops for irrigation scheduling?: A review of current knowledge and future perspectives. Agric. Water Manag. 97, 1-11.

Othman, Y., Vanleeuwen, D., Heerema, R., Hilaire, R. St., 2014. Midday stem water potential values needed to maintain photosynthesis and leaf gas exchange established for pecan. J. Am. Soc. Hort. Sci. 139, 537-546.

R. Core Team, 2016. R: A Language and Environment for Statistical Computing. R Foundation for Statistical Computing, Vienna, Austria https://www.R-project. org/.

Rosecrance, R.C., Krueger, W.H., Milliron, L., Bloese, J., Garcia, C., Mori, B., 2015. Moderate regulated deficit irrigation can increase olive oil yields and decrease tree growth in super high density Arbequina olive orchards. Sci. Hort. 190, 75-82.

Scholander, P.F., Hammel, H.T., Bradstreest, E.A., Hemmingsen, E.A., 1965. Sap pressure in vascular plant. Science 148, 339-346.

Shackel, K.A., Ahmadi, H., Biasi, W., Buchner, R., Goldhamer, D., Gurusinghe, S. Hasey, J., Kester, D., Krueger, B., Lampinen, B., McGourty, G., Micke, W. Mitcham, E., Olson, B., Pelletrau, K., Philips, H., Ramos, D., Schwankl, L., Sibbett S., Snyder, R., Southwick, S., Stevenson, M., Thorpe, M., Weinbaum, S., Yeager, J., 1997. Plant water status as an index of irrigation need in deciduous fruit trees. HortTech 7, 23-29.

Torres-Ruiz, J.M., Diaz-Espejo, A., Morales-Sillero, A., Martin-Palomo, M.J., Mayr, S. Beikircher, B., Fernández, J.E., 2013. Shoot hydraulic characteristics, plant water status and stomatal response in olive trees under different soil water conditions. Plant Soil 373, 77-87.

Turner, N.C., 1990. Plant Water relations and irrigation management. Agric. Water Manag. 17, 59-73.

Xiloyannis, C., Pezzarossa, B., Jorba, J., Angelini, P., 1988. Effects of soil water content on gas exchange in olive trees. Adv. Hort. Sci. 2, 58-63. 